\title{
Design Evolution and Innovation for Tropical Liveable Cities: Towards A Circular Economy
}

\author{
Katja Fleischmann
}

James Cook University Australia

\begin{abstract}
Design has become an important driver of economic innovation and better living globally. This paper looks at the evolution of design within the innovation space and how it is applied in tropical Singapore, a global financial center, and Townsville, a regional city in Australia's tropical northeast. The general question of whether regional Australian cities can adopt and adapt large scale innovative practices is examined in the context of driving change in the Circular Economy. The role of design has evolved from the popular understanding of creating products, driving consumption and being a decorative discipline; to driving social, public and economic change. Cities like Singapore have been on the policy forefront to push design-led innovation to facilitate start-ups, spark economic development, reimagine its future, and on a human scale, harmonize with its tropical setting. Design Thinking and Service Design Thinking as strategies for innovation play a crucial part in driving a paradigm shift in economic thinking away from unsustainable levels of consumerism and towards a Circular Economy. The future challenge for designers working toward a Circular Economy will require new ways of approaching services, processes and products that are good for business and sustainable development. Through higher education, Townsville design students took innovative steps to improve the quality of life for the elderly on a small scale, which illustrates a capacity for design-led innovation on a regional level that reflects large scale Service Design in Singapore.
\end{abstract}

Keywords: Design-led innovation, Circular Economy, human-centred design, Service Design Thinking, tropical cities 


\section{Introduction: opening up possibilities}

Design is about finding solutions, practical innovations, and making improvements that enhance people's lives, address problems or open up possibilities for a better life. (Burkett, 2012)

$\mathrm{D}$ esign has become an engine for change in a world that is fast depleting its resources at an unsustainable pace. As a response to these changes, thought leaders from many disciplines are increasingly employing designers to act as facilitators of problem solving in industries and services far removed from designers' traditional roles as creatives in shaping products, graphics and aesthetic artefacts. The Design Thinking process has found acceptance as a flexible, collaborative platform to help solve social and economic problems (Brown, 2009) which aligns Design Thinking well with dynamic systems like the Circular Economy.

The Circular Economy is a paradigm shift in economic thinking that is based on preserving and re-using what is produced - from finished consumer products to raw materials - instead of an endless cycle of exploitation which will exhaust our planet's resources and fuel unsustainable levels of consumerism. Using design-led innovation methodologies such as Service Design Thinking can help businesses transitioning to a Circular Economy - and make our cities and regions more liveable in the future.

"The Tropics has outperformed the Rest of the World in terms of economic growth over the past 30 years....By 2050 more than half of the world's population is expected to live in the Tropics" (James Cook University, 2014, p. 5). With this growth in population come economic and social pressures that will require new ways of approaching design to solve large scale issues, which is why design-led innovation is taking center stage as a change agent in reshaping economies and social services. Singapore, a tropical city-state and global financial centre embodies and is fostering this human-centered design-led innovation to nurture sustainable social and business practices. This paper examines how tropical cities like Singapore can inspire the cultivation and incorporation of design-led innovation in tropical regional Australia using Townsville, Queensland as a focal point.

\section{Design as an evolving discipline}

The popular conception of designers imagines them as creating products and visual aesthetics (Brown \& Wyatt, 2010; Ramirez, 2011). In reality, the area of design spans a wide range of sub-disciplines, which the Design Institute of Australia (DIA) classifies as: Industrial design, Interior architecture design, Interior decoration, Graphic design/Visual communication, Textile design, Exhibition design, Fashion design, Design management, Jewellery Design, Furniture design, Digital media design, and other new design specialisations emerging through technological advancements (DIA, 2017). Each of these design sub-disciplines have their own 
market niche, distinct professions, education programs, research areas and professional journals.

The emergence of the internet has created a wealth of new design professions. For example, in Graphic design/Visual communication and Digital media design there are now web designers, interactive media designers, information designers, game designers and user experience designers. In 2009, the demand for designers was predicted to grow ten percent in the next decade (Atkisson, 2009). This growth trend can also be seen in Australia, in particular for "'new" careers such as digital designers' (Seek Learning, 2015). Job opportunities for multimedia, digital media and interactive media designers are predicted to grow strongly in the future and will create between 10,001 and 25,000 new jobs through 2020 (Australian Government, 2017a). Technological advancement will also affect other design professions that have not been particularly technology-driven in the past. For example, Interior design will see strong growth in the future. In Australia, up to 10,000 interior design job openings are predicted to be available until 2020 (Australian Government, 2017b). James (2015) foresees a future for interior designers where "Your room will know what colour and brightness it should have the same way that Google knows what you're searching for before you finish typing your query".

Data designers - an emerging profession - will also be in high demand as the world becomes more driven by numbers that need to be interpreted and presented in a way that can easily be understood. Rolston (2014) calls this new profession the "most important new creative role of the next five years....The new design challenge is to use this data for the same humanistic outcomes that we have in mind when we shape products through the user interface or physical form".

\section{Design as a transformative practice that drives social and economic changes}

The evolution of design from a style-driven focus to a systematic way of thinking can be integral in economic growth and innovation which is why governments are funding projects that incorporate design into organisational change and economic planning (Design Council, 2011; Storvang, et al., 2013; Gulari, et al., 2017). Right now, design influences all aspects of society (Irwin, 2015), from the functioning of services and systems to how people communicate, shop, learn and interact with each other locally and globally. It is the humancentred focus of design that has opened the doors of design to evolve into a catalyst for change. Human-centred design starts with exploring the needs of people and develops solutions based on their needs (Fleischmann, Visini \& Daniel, 2012). Design-led innovation goes even further and involves all stakeholders in the design process. Now Service Design Thinking pushes the boundaries of design innovation by addressing the foundation of all service levels - from individual touchpoints to the organisation-wide strategic level - in order to create a better customer or user experience. Service Design is essentially a holistic planning framework which helps service providers better design how they deliver a product, experience, or service. It involves "the process of planning and organizing people, technology and material 
components" and has the goal "to enhance the quality of interactions between customers and providers” (Prendeville \& Bocken, 2017, p. 292).

Service Design Thinking can be applied to enhance interactions in any sector: economic, public or social. Governments, organisations or enterprises can use Service Design Thinking to enhance customer or user interactions, or interactions amongst these sectors. It is the systematic mapping of complex relationships and stakeholder interactions to facilitate innovative idea generation that makes Service Design Thinking an approach suitable to help solve some of today's complex problems. Service Design Thinking is held together by five principles identified by Stickdorn and Schneiderm (2011, p.34). Service Design Thinking is:

1. User-Centered: services should be experienced through the customer's eyes. Hence people are the centre of the service. 2. Co-Creative: all stakeholders should be included in the service design process. For example through co-creation. 3. Sequencing: the service should be visualised as a sequence of interrelated actions. Thus key moments (touchpoints) in a customer's journey need to be visualised. 4. Evidencing: intangible services should be visualised. 5. Holistic: the entire environment of a service should be considered. Hence context matters.

Service Design Thinking is part of the evolution of design. It has evolved from creating something visually pleasing into playing a central role in driving economic development and making our lives more meaningful through creative paradigms based on careful thought and inclusion.

\section{Designing liveable cities: Service Design Thinking towards the Circular Economy}

The strength of Service Design Thinking is a systematic understanding of the networked interactions and motivations which are key to identifying circular opportunities and hence transition to a Circular Economy. The Circular Economy is an attempt to break out of what is seen globally as the wasteful practices of increasing exploitation of scarce natural resources and planned obsolescence of products that feed an unsustainable system of cheap consumer credit and endless growth. In an effort to break this paradigm, the Circular Economy dispenses with the linear economy's Take-Make-Use-Dispose process and replaces it with the MakeRemake-Use-Reuse paradigm. The Ellen MacArthur Foundation et al. (2015) - a charity organisation and thought leader of the Circular Economy - has visualised the functioning of the Circular Economy in a diagram (Figure 1).

The Circular Economy is designed around a closed-loop, efficient system based on the concept of biomimicry. Natural systems are homeostatic - in other words, able to selfregulate, recycle, and as a result, are generally resilient and adaptable to environmental changes. There is no waste because nature recycles and re-uses "products" efficiently. The Circular Economy strives to mimic balanced natural systems. 


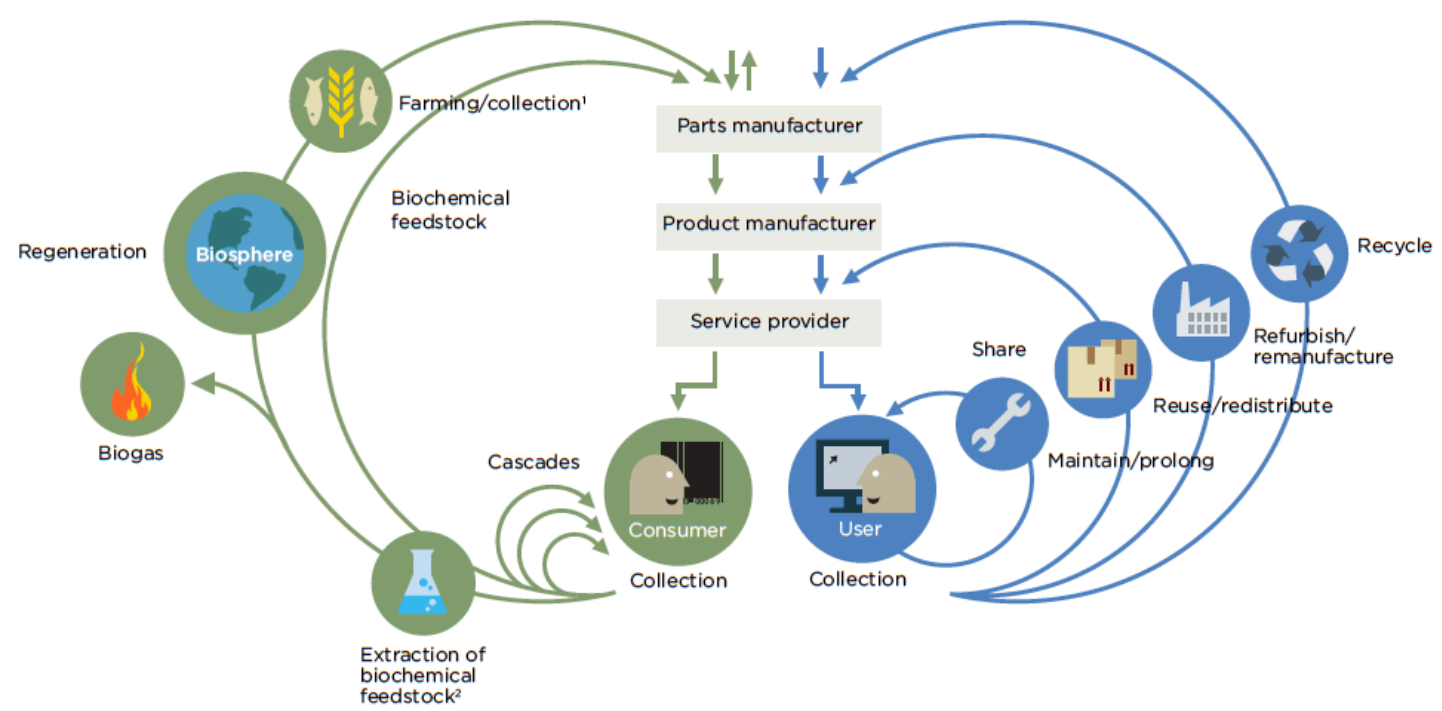

Figure 1. Outline of a Circular Economy (detail) (Ellen MacArthur Foundation et al., 2015, p. 24)

There is good reason to employ Circular Economy practices because currently the waste keeps piling up - only $14 \%$ of plastic packaging is recycled with the remainder discarded as waste, a potential loss of $\$ 80-\$ 120$ billion (Ellen MacArthur Foundation, 2017). These are the kinds of statistics that have European countries mandating large scale Circular Economy practices. Some member states are implementing large scale waste minimisation programs and achieving immediate economic benefits. These European countries have ambitious goals to reach an equilibrium between waste and use (Braw, 2014). For example, Denmark is hoping to halve all household waste by 2022. Currently about a quarter of household waste is recycled or incinerated. In the Netherlands, new targets were recently set with the aim of reducing waste-to-incineration by $50 \%$. The country has also set itself the target of $75 \%$ waste-sorting and separation at the source. And Sweden has passed a law that requires retailers selling electronic goods to accept the same quantity for reuse or recycling. Sweden also has plans to increase the recycling of metal and paper goods.

The Ellen MacArthur Foundation puts the net economic value of the Circular Economy in Europe at $€ 1.8$ trillion by 2030 (Ellen MacArthur Foundation et al., 2015). However, it is not just Europe that is driving the ideas behind a Circular Economy. There is a growing global recognition of the huge lost economic opportunity that could be recovered by Circular Economy practices. The World Economic Forum estimates that $80 \%$ of the US $\$ 3.2$ trillion value of the global consumer goods sector is lost to the inefficient linear economy.

Some Asian economies are taking a leadership role in implementing Circular Economy practices. Japan, for example, recycles $98 \%$ of its metals and a fraction of its waste ends up in landfills. There are good reasons for these high rates for recycling, re-use and remanufacturing in Japan. The country is densely populated, with little space for landfills and there is limited domestic metal production. And, importantly, Japan business culture is highly collaborative and takes a cradle-to-grave approach in production (Benton \& Hazell, 2015). 
China has also been singled out as a country that is moving its manufacturing processes toward circular practices. For example, the country has taken a fiscal incentive approach to encourage tyre manufacturers to use rubber powder from recycled tyres or re-tread older tyres. Hundreds of companies are now engaged in this business, which exempts them from VAT tax (Anbumozhi, 2017).

Cheam (2015) reports that the China Association of Circular Economy estimates that the country's Circular Economy is worth $\$ 283$ billion USD. Cheam also reports that South Korea and Taiwan demand that manufacturers recycle $75 \%$ of their annual production.

Singapore's artificial Jurong Island is also showcased as a good example of the Circular Economy. The island is home to the city-state's chemical and energy industry where one refinery's waste is used as another refinery's feedstock, thus designed according to maximising the value chain of production.

These circular economy initiatives require a re-thinking and re-design of the value chain and a collaborative effort to make it happen, whether it is required by an industrial process or in a social program.

\section{Innovation for liveable cities: designer as innovator and game changer in the tropics}

Singapore is a tropical city that embodies this shift to human-centered design. The city-state, which sits close to the equator, has been on the policy forefront to push design-led innovation to facilitate start-ups, spark economic development, re-imagine its future, and on a human scale, harmonize with its tropical setting.

Singapore is part of UNESCO's Creative Cities Network and has been designated as a Creative City of Design since 2015. UNESCO cites design as 'the key driver' of Singapore's creative economy (UNESCO Creative Cities Network, 2015). The DesignSingapore Council (established in 2003 to drive and promote design innovation) put the economic value of design businesses in Singapore at an estimated \$34 billion in 2015.

As a Creative City of Design, Singapore has a strategy that envisions:

- extending the training programmes of the Design Thinking \& Innovation Academy, focusing on design as an enabler of sustainable growth, productivity and prosperity;

- addressing the specific needs of the elderly population through the "Public Service Transformation" programme to adapt urban services and therefore enhance the quality of life of the elderly in the city;

- encouraging cross-disciplinary approaches through the implementation of the "National Design Centre - Cross-creative collaborations" workshops, mixing design with crafts and folk art and gastronomy; 
- organizing an exhibition showcasing best practices and projects of the Creative Cities of Design, to serve as a dialogue platform while enhancing international networking for urban planners and designers; and

- promoting multidisciplinary projects, highlighting the contribution of design to global sustainable urban development. (UNESCO Creative Cities Network, 2015)

Part of Singapore's plan is to introduce Design Thinking into early education and to inform decisions made in important government sectors. Jeffrey Ho, the Executive Director of the DesignSingapore Council, has commented that Design Thinking needs to be applied in all aspects of Singaporean life starting from an early age where it is taught in schools (Chin, 2016). Ho gives examples of Design Thinking employed in hospitals and clinics to organise space better to help the elderly, even down to chair design; in family courts, where mediation and counselling rooms are available to help defuse tense emotional situations; and in public housing which is designed to foster racial integration rather than allow the formation of ethnic group ghettos. This type of social engineering has been linked to Singapore's economic growth (Tulshyan, 2015).

Economic growth is not the sole focus of Design Thinking, or its more recent evolution, Service Design Thinking; it is also used to tackle social issues (Fleischmann, 2013) and make living in the city a more harmonious experience. For example, the DesignSingapore Council, together with the National Council of Social Services and Veryday, a design consultancy, have been engaged in designing a blueprint to make life better for disabled people (DesignSingapore Council, 2016; Veryday, 2016). The group has put together a roadmap to include services and a more inclusive life for the disabled using ethnographic research methods (e.g. journey mapping, contextual interviews and shadowing), co-analysis and cocreation - the cornerstones of Service Design Thinking.

\section{Design-led innovation in a Circular Economy - the biggest challenge yet?}

Because of its structured design culture, Singapore is also well positioned to deal with its big city problems. Singapore - which is just two-thirds the size of New York City, but about twice the size of Manhattan Island - currently imports half of its water from Malaysia and annually disposes of 200,000 tonnes of its solid waste on a man-made island. Its waste island, Semakau, is also an eco-reserve (Jia \& Aziz, 2016). Waste minimisation and capturing natural resources is just part of what Singapore is doing to promote the Circular Economy, which the city has embraced - albeit on a small scale.

Singapore has been listed as the sixth most innovative economy in the world as it continues to develop an entrepreneurial ecosystem that is attracting fresh ways of thinking, cross-industry collaborative possibilities and some of the world's most innovative companies (Gin, 2017). The citystate is poised to be a driver of the Circular Economy. A recent gathering of industry leaders in Singapore singled out design-led innovation as instrumental in helping companies keep up with 
technological disruptions to markets (Toh, 2017). Singapore's Nanyang Environment and Waste Water Research Institute, for example, is working on the creation of green construction materials made from brine waste from a desalination plant (The Holland Innovation Network, 2017).

Singapore, has its own Circular Economy network (http://www.circularsg.com). The network consists of mostly small enterprises that are basically demonstrating proof-of-concept by recycling and reusing textiles and other disposable materials. The network members include businesses that re-use clothing and cast-offs to make jewellery; another company helps design green food packaging; one holds repair workshops to keep repairable goods in circulation. Jimmy Lea is also part of the network. The engineering consulting firm specializes in Plant Engineering and Computational Fluid Dynamics. And it also offers strategies to minimise waste and consumption of raw materials.

As an affluent city-state, Singapore is in a solid economic position to attract investment and push innovation through government sponsorship. Many developing Asian countries with economies driven by small and medium-sized enterprises (SMEs) are largely undercapitalized and have a more difficult time encouraging design-led innovation. In the Australian context, Singapore provides a good example of how central government decision-making and policy can drive design-led innovation toward employing Circular Economy practices.

\section{Casting the design-led innovation lens on Townsville}

In Australia, some states (South Australia, Victoria and New South Wales) are taking the lead in turning Circular Economy ideas into reality. South Australia, in particular, is part of the circular equation, where the government is currently looking into supporting a transition through policy changes. The state predicts that the Circular Economy can create more than 25,700 new full-time jobs and reduce greenhouse gas emissions by $27 \%$ by 2030 (Green Industries SA, 2017).

Design-led innovation can have a positive impact on regional economies that want to begin participating in the Circular Economy. The innovative practices, however, need to be available as an employable creative service. Townsville, a city located in the tropical north of Queensland in Australia, is one such regional centre that has yet to tap into the innovation capabilities provided by its creative community. Like many regional centres in Australia (e.g. Cairns, see Daniel 2013), Townsville has not invested in its creative industries to drive economic innovation. A survey of of approximately a quarter of creative industries in Townsville (Fleischmann, Daniel \& Welters, 2017) found that creative businesses in Townsville do offer design-led innovation services, however there is only a low market demand for the kind of design innovation that would stimulate Circular Economy practices. Most local Townsville businesses spend their money on traditional advertising and media services. A possible reason is that Townsville businesses have little motivation or no incentive to innovate.

In order to change this traditional mindset, design programs at the university level, such as the local James Cook University (JCU) in Townsville, need to dive into the future with concepts 
that will drive economic change, and feed systems like the Circular Economy. First steps have been undertaken to educate designers in order that they can tackle complex societal, economic and environmental problems of our society. Similar to Singapore, at JCU in Australia, design students have used Design Thinking and current technology to engage with the elderly to tackle complex questions like: "How can we change the social stigma surrounding the elderly?" and "How can we encourage companionship in elderly lives to fight loneliness?"

In this project, students worked in design groups or multidisciplinary teams using humancentred design methods and applying Design Thinking and the iterative process of designing. They researched, analysed, evaluated, synthesised and then conceptualised their ideas in a holistic systems-thinking approach, while involving the elderly throughout the process, to create desirable and useful experiences. Students created their service ideas by interviewing end users and employed a wide range of design methods which included the use of scenarios and personas, contextual interviewing, user shadowing, and experience prototyping. A practical outcome of this work was the "Travel Buddy" app which focused on housebound elderly people who would still like to experience the joys of travel. The app was designed to overcome the mobility limitations of many housebound elderly people (Figure 2).
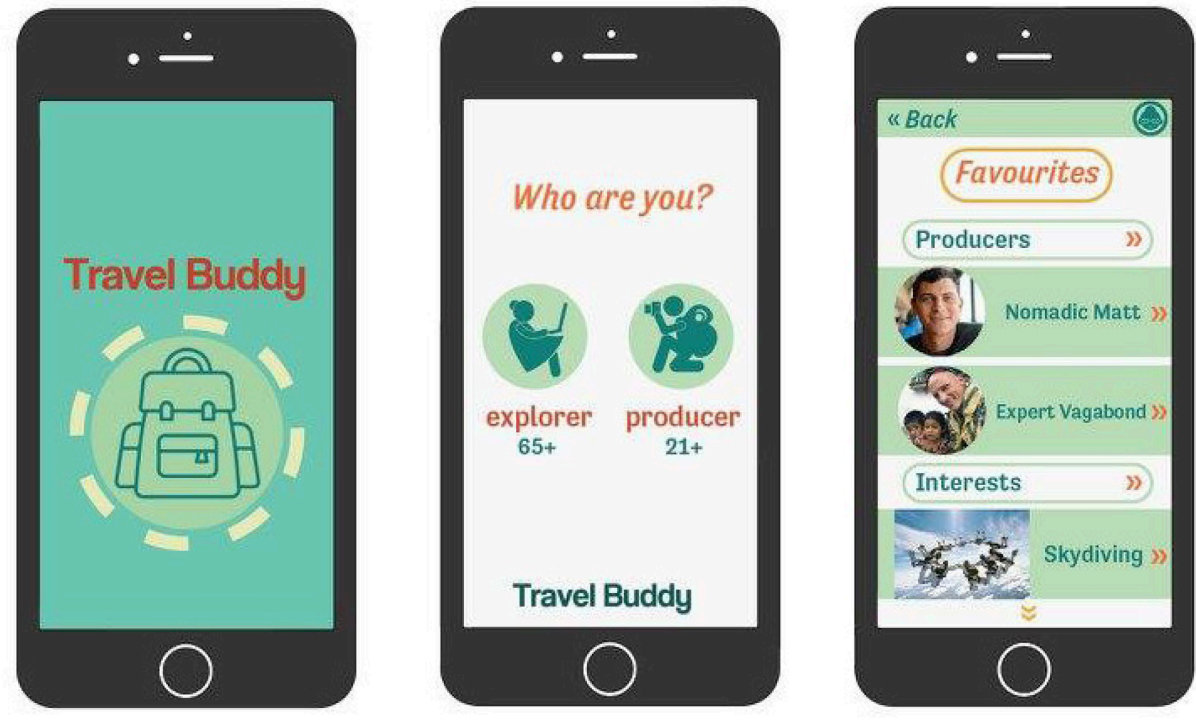

Figure 2. Travel Buddy app

Travel Buddy connects an elderly "explorer" with a younger "producer" and allows the elderly to immerse themselves in another person's travel experience. This is done through social media applications such as shared video footage, audio feeds and chat rooms which provide an interactive experience that is as close to a real-life experience as possible. Elderly people are able to tick items off the travel list in a safe environment and their social engagement improves. Giving back to the community and breaking down the social isolation of the elderly rewards producers as well. The app is designed to run on a crowd-sourced donation model allowing producers to fund their travels. 


\section{The role of education in creating new designers}

Starting next year design students at JCU in northern Australia will learn to use Service Design Thinking in a Circular Economy context. It is critical that designers understand and apply the concept of "circularity" to their studies. Some universities, notably the Delft University of Technology in the Netherlands, are already teaching concepts of Circular Economy in a design context. Those courses are now inspiring design students to put concepts into practice. Two alumni from the University of Delft developed a modular headphone which they provide to customers on a subscription basis (Looijse, 2017). The business model is based on the Circular Economy idea of leasing a product rather than owning it, which theoretically creates a cheaper and more sustainable product. In this model, customers pay to use the headphones on a monthly or yearly basis, which entitles them to upgrades and repairs. The idea has not turned into a viable business because of struggles building the Gerrard Street brand (https://gerrardst.nl/). Researchers were tasked with helping re-focus the brand through surveys.

An integrated product design thesis (Kane, 2016) published at the Faculty of Industrial Design Engineering at Delft University of Technology, addressed the Circular Economy idea of refurbishing medical equipment that was donated to developing nations. When equipment was broken, it was dumped. The thesis provides a model for designing a product-service for repair and maintenance of medical imaging equipment in Africa. The thesis provided a platform for remote-servicing on mobile devices.

Another prime example comes from Sicily, which generates hundreds of tonnes of solid waste from its orange juicing industry. An entrepreneurial design student in Milan has started a company that chemically converts the orange rinds into silk-like materials that are used in clothing manufacturing (Marchese, 2017). The company, Orange Fiber, operates from a local juice-processing plant and gets its material for free. High-end Italian fashion label Salvatore Ferragamo used the orange fibre product in its spring and summer collection.

\section{Conclusion: Designing a more liveable future}

Entrepreneurship encouraged by forward thinking educational institutions - backed by policy and financial incentives from local, regional, and national governments - need to combine to become a driver for design-led innovation in a Circular Economy. As we have seen, the Circular Economy requires a radical re-thinking of design processes in all aspects of the consumer-manufacturing value-chain cycle. Successful Circular Economy businesses reimagine products, services and markets to accommodate a waste minimisation strategy.

As the hub of manufacturing in the world, fast growing Asian economies are developing Circular Economy practices that can become a role model for regional Australian cities such 
as Townsville. Tropical Singapore is one such country that has adopted Service Design Thinking as a driver to improve the lives of its citizens. Its success is based on central government sponsorship and a culture of design-innovation that has been embraced and pushed forward into Singaporean society.

Because of its dense population and limited land space, Singapore has been required to innovate. Regional Australian cities can adopt the Singapore model on a smaller scale by engaging local businesses and providing incentives to engage designers who can implement the processes that, not only save time and money, but also introduce a circular way of doing business.

A creative mindset drives the Circular Economy and that is what Townsville can take away from Singapore. To tackle some of Townsville's problems and implement Circular Economy practices, there is no reason why regional councils in Australia could not engage design students in solving problems that fall under the Circular Economy umbrella. What is needed is the human-centred perspective. This is precisely the paradigm that designers have always practiced, where the iterative process has yielded solutions to complex problems. At its core, design has developed into a systematic approach to problem solving that can provide a framework for Circular Economy implementation and pave the way for better living - in the tropics - and globally. 


\section{References}

Anbumozhi, V. (2017). Asian Countries Can Be Global Leaders in Developing Circular Economies. ERIA. Retrieved from http://www.eria.org/opinion/FY2017/07/asiancountries-can-be-global-leaders-in-developing-circular-economies.html

Atkisson, V. (2009). 10 Fastest Growing Design Jobs. ARTBistro. Retrieved from http://artbistro.monster.com/careers/articles/8794-10-fastest-growing-design-jobs

Australian Government. (2017a). Job Outlook- Graphic and Web Designers, and Illustrators. Retrieved from http://joboutlook.gov.au/occupation.aspx?code=2324

Australian Government. (2017b). Job Outlook- Interior Designer. Retrieved from http://joboutlook.gov.au/occupation.aspx?code=2325

Benton, D., \& Hazell, J. (2015). The circular economy in Japan. Retrieved from https://www.the-ies.org/analysis/circular-economy-japan

Braw, E. (2014). Five countries moving ahead of the pack on circular economy legislation. The Guardian. Retrieved from https://www.theguardian.com/sustainablebusiness/2014/oct/29/countries-eu-circular-economy-legislation-denmark-swedenscotland

Brown, T. (2009). Change by Design: How Design Thinking Transforms Organizations and Inspires Innovation. New York: HarperCollins.

Brown, T., \& Wyatt, J. (2010). Design Thinking for Social Innovation. Stanford Social Innovation Review (Winter), 31-35.

Burkett, I. (2012). What is Social Design? Retrieved from https://secure.csi.edu.au/site/Home/Blog.aspx?defaultblog=https://blog.csi.edu.au/20 12/01/what-is-social-design/

Cheam, J. (2015). The rise of the circular economy in Asia. Retrieved from http://www.ecobusiness.com/news/rise-circular-economy-asia/

Chin, C. (2016). How is Design-Thinking reshaping Singapore? GovInsider. Retrieved from https://govinsider.asia/innovation/how-is-design-thinking-reshaping-singapore/

Daniel, R. (2013). Creativity and creative industries in Cairns: views from the field. Etropic: electronic journal of studies in the tropics, 12(2), 58-69.

Design Council. (2011). Design for Innovation: Facts, figures and practical plans for growth. Retrieved from http://www.designcouncil.org.uk/publications/Design-for-Innovation/

DesignSingapore Council. (2016). The Path To...Better Life by Design. Retrieved from https://www.designsingapore.org/what-we-do/resources/the-path-to-better-life-bydesign

DIA. (2017). Design Disciplines. Retrieved from https://www.design.org.au/designindustry/design-disciplines

Ellen MacArthur Foundation, SUN, \& McKinsey Center for Business and Environment. (2015). Towards the Circular Economy, Economic and Business Rationale for an Accelerated Transition. Retrieved from https://www.ellenmacarthurfoundation.org/assets/downloads/TCE_Ellen-MacArthurFoundation 9-Dec-2015.pdf 
Ellen MacArthur Foundation. (2017). The new plastics economy-catalysing action. Retrieved from https://www.ellenmacarthurfoundation.org/assets/downloads/New-PlasticsEconomy Catalysing-Action 13-1-17.pdf

Fleischmann, K. (2013). Social entrepreneurs and social designers: Change makers with a new mindset? International Journal of Business and Social Science, 4(16), 9-17.

Fleischmann, K., Visini, G., \& Daniel, R. (2012). We want to add to their lives, not take away.... In P. Rodgers (Ed.), Articulating Design Thinking (pp. 107-133). Faringdon: Libri.

Fleischmann, K., Daniel, R., \& Welters, R. (2017). Developing a regional economy through creative industries: Innovation capacity in a regional Australian city. Creative Industries Journal. doi:10.1080/17510694.2017.1282305

Gin, B. S. (2017). Singapore's long game in innovation. The Straits Times - Economic Affairs. Retrieved from http://www.straitstimes.com/opinion/singapores-long-game-ininnovation

Green Industries SA. (2017). Benefits of a Circular Economy in South Australia Summary. Retrieved from http://www.greenindustries.sa.gov.au/ _literature_172176/Benefits_of_a_Circular_Economy_in_South_Australia_summary_(2017)

Gulari, M. N., Melioranski, R.-H., Er, O., \& Fremantle, C. (2017). The future of design support: What Can We Learn From Design Support Experience in the UK, Estonia and Turkey? Paper presented at the Design for Next, 12th EAD Conference, Sapienza University of Rome.

Irwin, T. (2015). Transition Design: A Proposal for a New Area of Design Practice, Study, and Research. The Journal of the Design Studies Forum, 7(2), 229-246. doi:10.1080/17547075.2015.1051829

James, G. (2015). How Digital Technology Will Change Interior Design. LinkedIn. Retrieved from https://www.linkedin.com/pulse/how-digital-technology-change-interior-designgary-james

James Cook University. (2014). State of the Tropics. Retrieved from https://www.jcu.edu.au/state-of-the-tropics/publications/2014

Jia, J. C. Y., \& Aziz, N. (2016). Pulau Semakau. National Library Board Singapore, Singapore Government. Retrieved from http://eresources.nlb.gov.sg/infopedia/articles/SIP_1008_2010-03-22.html

Kane, G. (2016). Designing a product-service for repair \& maintenance of medical imaging equipment in Africa. Delft University of Technology. Retrieved from https://repository.tudelft.nl/islandora/object/uuid:168b31c2-47a6-4c29.../download

Looijse, K. (2017). Headphones as a service. Repository Delft University of Technology. Retrieved from https://repository.tudelft.nl/islandora/object/uuid\%3A591c9491-fdbc40e3-9b99-a69ff488682c?collection=education

Marchese, F. (2017). How Sicilian oranges are being made into clothes. BBC Business. Retrieved from http://www.bbc.com/news/business-40946159

Prendeville, S., \& Bocken, N. (2017). Sustainable Business Models through Service Design. Procedia Manufacturing, 8, 292-299. 
Ramirez, M., Jr. (2011). Designing with a social conscience: An emerging area in industrial design education and practice. Paper presented at the International Conference on Engineering Design, ICED11. , Technical University of Denmark. http://unsworks.unsw.edu.au/fapi/datastream/unsworks:10520/SOURCE01

Rolston, M. (2014). The next era of designers will use data as their medium. WIRED. Retrieved from https://www.wired.com/2014/11/rise-of-data-artists

Seek Learning. (2015). Industries that are hiring in 2015. Retrieved from https://www.seeklearning.com.au/study-and-career-advice/seek-job-trends/industriesthat-are-hiring-in-2015

Stickdorn, M. \& Schneider, J. (2011). This is Service Design Thinking: Basics, Tools, Cases. BIS Publisher, The Netherlands.

Storvang, P., Jensen, S., Christensen, P.R. \& Storgaard, M. (2013). 'Facilitating Innovation through Design in a Danish context - a framework for design capacity'. Paper presented to 2nd Cambridge Academic Design Management Conference, University of Cambridge, 4 - 5 September.

The Holland Innovation Network. (2017). Singapore - Towards Resource Recovery in a Circular Economy. Retrieved from https://www.netherlandsworldwide.nl/latest/news/2017/04/21/singapore---towardsresource-recovery-in-a-circular-economy

Toh, M. (2017). Why Design Thinking Matters More in Business Than Ever. FORTUNE. Retrieved from http://fortune.com/2017/03/14/singapore-design-week-business/

Tulshyan, R. (2015). Singapore's forced housing integration fueled its economic success. Retrieved from https://qz.com/436056/singapores-forced-housing-integration-fueledits-economic-success/

UNESCO Creative Cities Network. (2015). Singapore. Retrieved from http://en.unesco.org/creative-cities/singapore

Veryday. (2016). Looking beyond normality. Retrieved from http://veryday.com/case/singapore-designsingapore-council/ 